\title{
COMPOSITION OPERATORS AND CLOSURES OF DIRICHLET TYPE SPACES IN LOGARITHMIC BLOCH-TYPE SPACES
}

\section{LIXU ZHANG}

Abstract. Closures of Dirichlet type spaces in logarithmic Bloch-type spaces are investigated in the paper. Moreover, the boundedness and compactness of composition operators from logarithmic Bloch-type spaces to closures of Dirichlet type spaces in logarithmic Bloch-type spaces are characterized.

Mathematics subject classification (2010): 30H30, 30H99, 47B33.

Keywords and phrases: Dirichlet type space, logarithmic Bloch-type space, composition operator.

\section{REFERENCES}

[1] J. Anderson, Bloch functions: the basic theory, Operators and function theorey (Lancaster, 1984), 1-17, NATO Adv. Sci. Inst. Ser. C Math. Phys. Sci. 153, Reidel, Dordrechet, 1985.

[2] J. Anderson, J. Clunie And Ch. Pommerenke, On Bloch functions and normal functions, J. Reine Angew. Math., 270 (1974), 12-37.

[3] R. AUlas KARI AND R. ZHAO, Composition operators and closures of some Möbius invariant spaces in the Bloch space, Math. Scand., 107 (2010), 139-149.

[4] G. BAO And N. GÖĞÜş, On the closures of Dirichlet type spaces in the Bloch space, Complex Anal. Oper. Theory, 13 (2019), 45-59.

[5] C. C. Cowen And B. D. MacCluer, Composition Operators on Spaces of Analytic Functions, CRC Press, Boca Raton, FL, 1995.

[6] P. Duren, Theory of $H^{p}$ Spaces, Academic Press, New York, 1970.

[7] P. Galanopoulos, $O n \mathscr{B}_{\log }$ to $Q_{\log }^{p}$ pullbacks, J. Math. Anal. Appl., 337 (2008), $712-725$.

[8] P. Galanopoulos And D. Girela, The closure of Dirichlet spaces in the Bloch space, Ann. Acad. Sci. Fenn., 44 (2019), 91-101.

[9] P. Ghatage And D. ZHeng, Analytic functions of bounded mean oscillation and the Bloch space, Integr. Equ. Oper. Theory, 17 (1993), 501-515.

[10] J. HAN AND Y. WU, The high order derivative characterization of logarithmic Bloch type spaces, J. Anhui Univ. Sci. Tech., 2(2013), 32-34.

[11] H. Li AND P. LIU, Composition operators between generally weighted Bloch space and $Q_{\log }^{q}$ space, Banach J. Math. Anal., 3(1) (2009), 99-110.

[12] S. LI, Differences of generalized composition operators on the Bloch space, J. Math. Anal. Appl., 394 (2012), 706-711.

[13] S. Li AND S. STEVIĆ, Generalized composition operators on Zygmund spaces and Bloch type spaces, J. Math. Anal. Appl., 338 (2008), 1282-1295.

[14] X. LiU AND S. Li, Norm and essential norm of a weighted composition operator on the Bloch space, Integr. Equ. Oper. Theory, 87 (2017), 309-325.

[15] Z. Lou, Composition operators on Bloch type spaces, Analysis (Munich), 23 (2003), 81-95.

[16] Z. LOU AND W. CHEN, Distances from Bloch functions to $\mathscr{Q}_{K}$-type space, Integr. Equ. Oper. Theory, 67 (2010), 171-181.

[17] K. Madigan And A. Matheson, Compact composition operators on the Bloch space, Trans. Amer. Math. Soc., 347 (1995), 2679-2687.

[18] N. Monreal Galán And A. Nicolau, The closure of the Hardy space in the Bloch norm, Algebra i Analiz, 22 (2010), 75-81, translation in St. Petersburg Math. J., 22 (2011), 55-59. 
[19] J. M. ORTega And J. FÀbrega, Corona type decomposition in some Besov spaces, Math. Scand., 78 (1996), 93-111.

[20] R. QIan AND S. LI, Composition operators and closures of Dirichlet type spaces $\mathscr{D}_{\alpha}$ in the logarithmic Bloch space, Indag. Math., 29 (2018), 1432-1440.

[21] R. QIAN AND S. LI, Composition operators and closures of Dirichlet type spaces $\mathscr{D}_{\mu}$ in Bloch type spaces, Anal. Math., 45(1) (2019), 121-132.

[22] S. Stevic And R. AgARwal, Weighted composition operators from logarithmic Bloch-type spaces to Bloch-type spaces, J. Inequal. Appl., (2009), Article ID 964814, 21 pages.

[23] M. TJANI, Compact composition operators on some Möbius invariant Banach space, $\mathrm{PhD}$ dissertation, Michigan State University, 1996.

[24] M. TJani, Distance of a Bloch function to the little Bloch space, Bull. Austral. Math. Soc., 74 (2006), $101-119$.

[25] H. Wulan, D. Zheng And K. Zhu, Compact composition operators on BMOA and the Bloch space, Proc. Amer. Math. Soc., 137 (2009), 3861-3868.

[26] R. YonedA, The composition operators on weighted Bloch space, Arch. Math. (Basel), 78 (2002), 310-317.

[27] R. ZHAO, Distances from Bloch functions to some Möbius invariant spaces, Ann. Acad. Sci. Fenn. Math., 33 (2008), 303-313.

[28] R. ZHAO, Essential norms of composition operators between Bloch type spaces, Proc. Amer. Math. Soc., 138 (2010), 2537-2546.

[29] K. ZHU, Operator Theory in Function Spaces, American Mathematical Society, Providence, RI, 2007. 